\title{
Sinus venosus atrial septal defect: a rare cause of misplacement of pacemaker leads
}

This article was published in the following Dove Press journal:

International Medical Case Reports Journal

3 July 2013

Number of times this article has been viewed

\author{
Malick Bodian' \\ Fatou Aw' \\ Mouhamadou Bamba \\ Ndiaye' \\ Adama Kane' \\ Modou Jobe' \\ Alioune Tabane' \\ Alassane Mbaye ${ }^{2}$ \\ Simon Antoine Sarr ${ }^{\prime}$ \\ Maboury Diao' \\ Moustapha Sarr ${ }^{\prime}$ \\ Serigne Abdou Bâ' \\ 'Department of Cardiology, Aristide \\ Le Dantec Teaching Hospital, ${ }^{2}$ Grand \\ Yoff General Hospital, Dakar, Senegal
}

Correspondence: Modou Jobe

Department of Cardiology, Aristide

Le Dantec Teaching Hospital,

BP 300 I Dakar, Senegal

Tel +221777026653

Fax +22 I3 38224746

Email modoujobe@gmail.com

\begin{abstract}
Routine implantation of pacemakers and implantable cardioverter defibrillators is not commonly associated with complications. However, in some cases we see misplacement of pacemaker leads which is most often related to the presence of underlying cardiac anomalies. We report the case of misplacement of a pacemaker lead into the left ventricle of a 56-year-old patient paced in VVI/R mode and with a tined type pacemaker lead because of a symptomatic complete atrioventricular block. Electrocardiogram showed a pacemaker-generated rhythm with a right bundle branch block pattern. Chest X-ray showed the pacemaker lead located relatively high in relation to the diaphragm. Echocardiography visualized the pacemaker lead in the left heart chambers (atrium and ventricle), hence confirming its aberrant course. Further, the defect causing its passage to the left heart chambers was a sinus venosus atrial septal defect. The patient reported no complication related to the misplacement of the lead. After a brief period of oral anticoagulation, the lead was inserted into the right ventricle by percutaneous technique.
\end{abstract}

Keywords: pacemaker, lead misplacement, sinus venosus atrial septal defect

\section{Introduction}

One of the complications associated with transvenous pacemaker implantation is the inadvertent passage of the pacing lead into the left ventricle. This is a rare complication ${ }^{1}$ and can be a source of arterial thromboembolism. We report here the case of a patient with pacemaker lead misplacement in the left ventricle through an aberrant path via a sinus venosus atrial septal defect.

\section{Case report}

A 56-year-old woman presented at consultation with stage III New York Heart Association dyspnea which had started 3 months prior to presentation. Clinical examination found systolic and diastolic hypertension of 200/90 $\mathrm{mmHg}$, auscultatory bradyarrhythmia of 42 beats per minute, and an apical systolic murmur with an intensity of 3/6. There was a complete atrioventricular block with narrow QRS complexes, at an atrial rate of 79 cycles per minute and a ventricular rate of 38 cycles per minute on surface electrocardiogram. Following this diagnosis, the patient underwent a single chamber pacemaker implantation (mode VVI/R) with a tined type pacemaker lead via the left cephalic vein. Post-implantation electrocardiography showed a pacemakergenerated rhythm with ventricular spikes and a right bundle branch pattern (Figure 1A), and chest X-ray showed the pacemaker lead located relatively high in relation to the diaphragm (Figure 1B). These findings lead us to consider possible misplacement of the lead which was confirmed by transthoracic echocardiography visualizing the pacemaker 

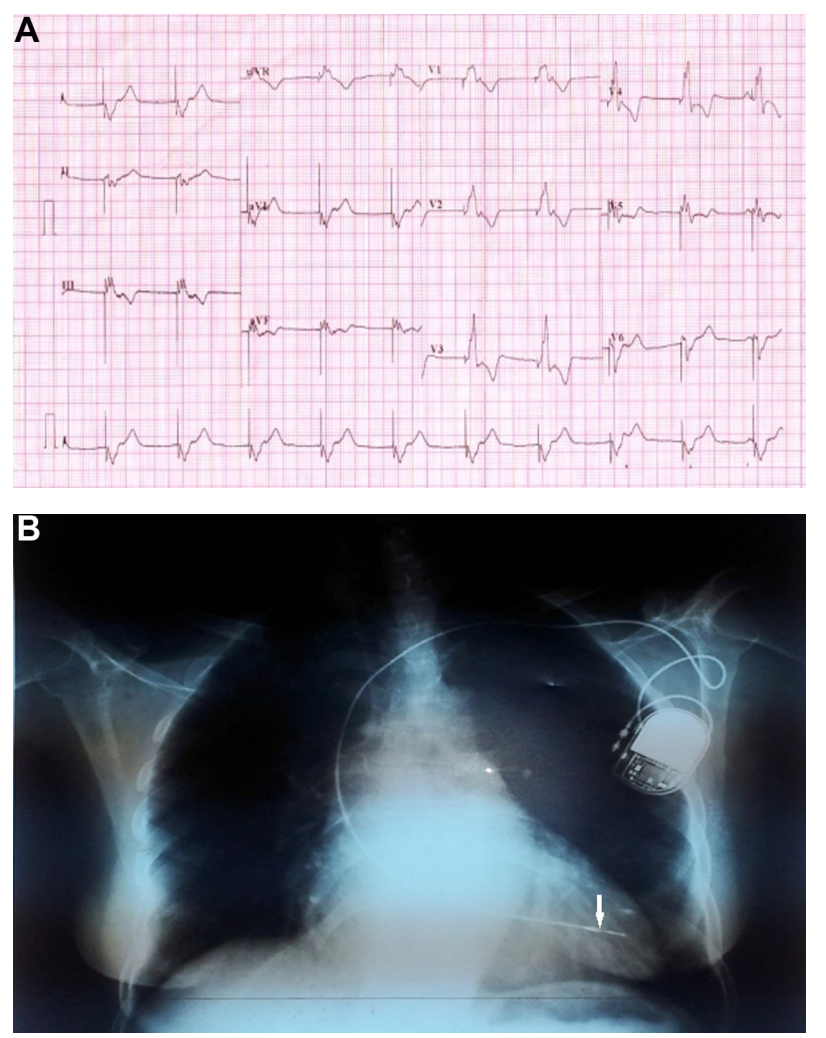

Figure I (A) Post-implantation electrocardiogram showing ventricular spikes and a right bundle branch block pattern. (B) Post-implantation chest X-ray showing the pacemaker lead (arrow) located relatively high in relation to the diaphragm.

lead in the left atrium and ventricle and its attachment to the posterior wall of the left ventricle (Figure 2A and B). There was no thrombus in contact with the lead. The mitral valve appeared normal without structural alteration. Doppler echocardiography found moderate biatrial and right ventricular dilatation and severe tricuspid regurgitation with moderate pulmonary hypertension. We noted the presence of a sinus venosus atrial septal defect (Figure 3A and B). Computed tomography scan of the chest, performed to look for a vascular malformation, found anomalous pulmonary venous return of the right upper pulmonary vein connecting to the superior vena cava. The patient underwent reinsertion of her pacemaker lead the right ventricle on day $12 \mathrm{in.} \mathrm{This}$ was confirmed by electrocardiogram (appearance of a left bundle branch block pattern, Figure 4) and by Doppler echocardiography.

\section{Discussion}

Transvenous implantation of a pacemaker or implantable cardioverter defibrillator lead into the left ventricle is a rare complication of cardiac pacing. ${ }^{1}$ The incidence of this complication is not precisely known, but since the advent of two-dimensional echocardiography, it is
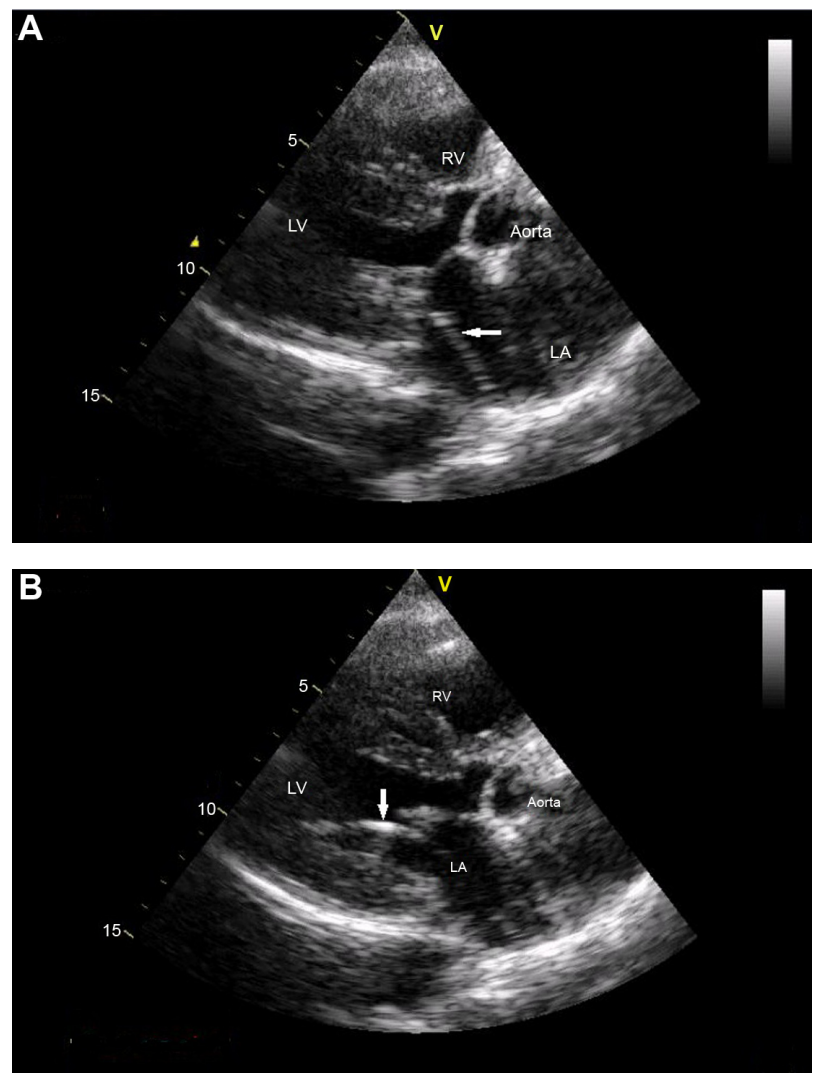

Figure 2 (A and B) Two-dimensional transthoracic echocardiography with a parasternal long axis view showing pacemaker lead (arrow) in the left heart chambers.

Abbreviations: $L A$, left atrium; $L V$, left ventricle; $R V$, right ventricle.

increasingly diagnosed., ${ }^{2,3}$ The pacemaker lead may enter the left atrium through a patent foramen ovale, or a sinus venosus, ostium primum, or ostium secundum atrial septal defect. ${ }^{4}$ However, it can also directly enter into the left ventricle via the aorta by accidental puncture of the subclavian artery ${ }^{5}$ or due to an interventricular septal defect. In our patient, we think that the presence of severe tricuspid regurgitation might have aided in directing the lead from the right atrium to the left atrium. Patients with lead misplacement in the left heart chamber may be asymptomatic ${ }^{6}$ or may present with complications secondary to arterial emboli. ${ }^{7}$ These thromboembolic events can be up to $37 \%$ in patients with lead misplacement in the left cavities, according to the literature. $^{8}$

The electrocardiogram is a useful diagnostic tool for detecting the position of a cardiac stimulation lead. ${ }^{9}$ Indeed, when the lead is inserted into the right ventricle, the electrocardiographic recording is of a left bundle branch block pattern. Hence the presence of a right bundle branch block pattern after implantation should raise suspicion for a misplacement of leads, as was the case in our patient. 

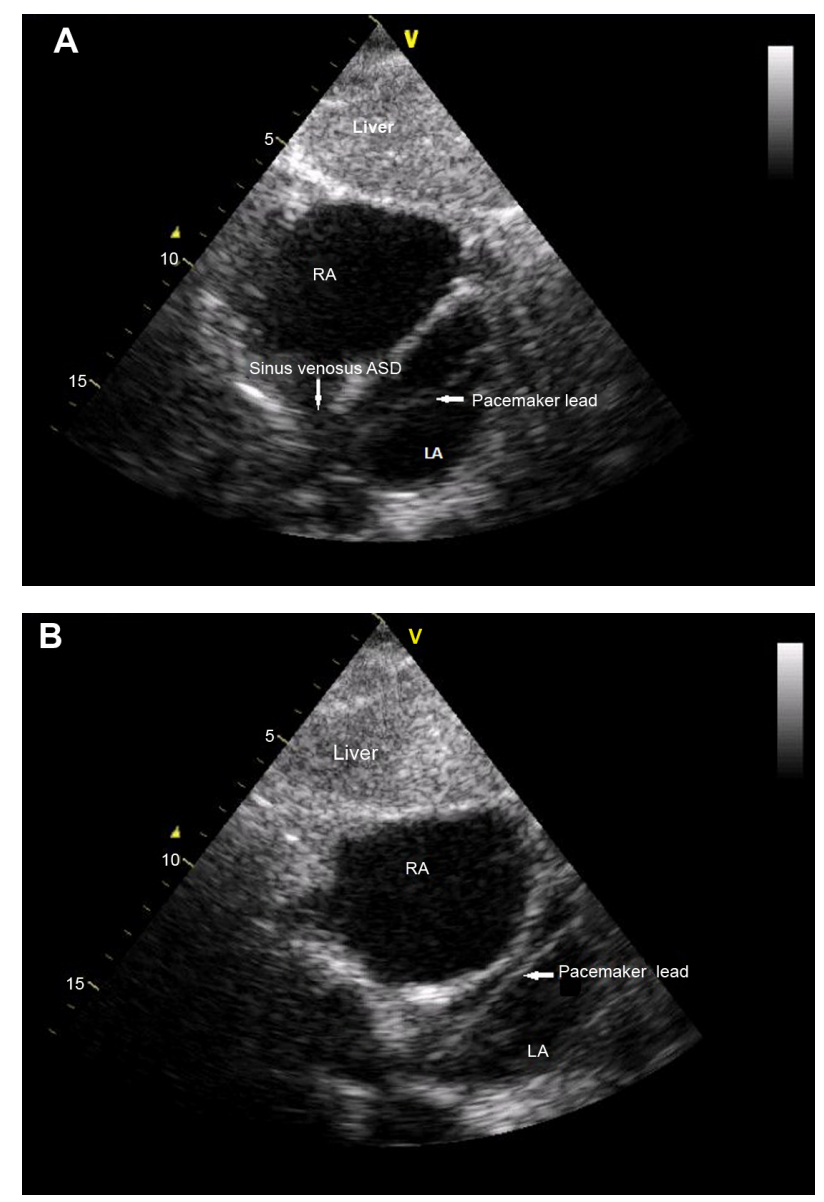

Figure 3 (A and B) Two-dimensional echocardiographic subcostal view showing the sinus venosus atrial septal defect (defect in the superior-posterior portion of the interatrial septum at the junction of the superior vena cava and right atrium). Abbreviations: ASD, atrial septal defect; LA, left atrium; RA, right atrium.

However, one should remember that this right bundle branch block pattern can also be seen in the case of lead placement in the coronary sinus ${ }^{10,11}$ or even occasionally in the apical region of the right ventricle. ${ }^{12,13}$ Chest X-ray with posterioranterior and lateral views can provide supplementary diagnostic arguments, as was the case in our patient. Indeed, for a correctly placed lead into the right ventricle, a lateral

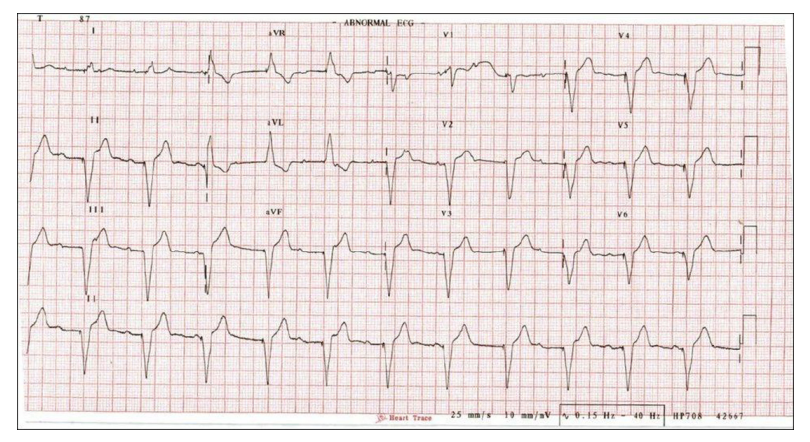

Figure 4 Post reimplantation electrocardiogram showing a left bundle branch block pattern, indicating the presence of the lead in the right cavities. chest X-ray shows the lead anterior and lateral to the sternum and above the diaphragm. On the other hand, a lead located relatively high above the diaphragm in the posterior-anterior view and more posteriorly placed relative to the sternum in the lateral view should suggest misplacement into the left ventricle.

In all cases, two-dimensional transthoracic echocardiography $^{2}$ is a more reliable diagnostic method. Indeed, it makes the diagnosis and helps in the search for the presence of cardiac anomalies causing lead misplacement in the left chambers. In its absence, we can use a computed tomography scan of the chest to visualize these cardiac anomalies better. In our case report, it was a sinus venosus atrial septal defect visualized by a transthoracic echocardiography subcostal view. This congenital cardiac anomaly results from faulty partitioning of the posterior interatrial septum, resulting in communication with the superior-posterior portion of the atrial septum at the junction of the superior vena cava and the right atrium. The right superior pulmonary vein overlaps the interatrial septum where it is directly implanted into the right atrium.

Once the diagnosis of misplacement is confirmed, the patient may simply be managed with anticoagulation ${ }^{8,14}$ or by properly reinserting the leads, considering the benefits and potential risks. ${ }^{14}$ However, we must acknowledge that since these rare cases were described in the literature, no consensus has been reached on the management of these patients. For patients with a high surgical risk, oral anticoagulation is recommended. It must be said that this option to leave the leads in place under anticoagulation treatment is valid because redoing the procedure is associated with infection. ${ }^{8,15}$ The other option is surgical removal of the lead with median sternotomy under cardiopulmonary bypass, which is associated with an infection rate of $4.5 \%$. However, Trohman et $\mathrm{al}^{16}$ described a case of percutaneous lead extraction in a patient who was initially anticoagulated and showed no obvious signs of thrombus in contact with the lead by transthoracic echocardiography. ${ }^{14}$ However, the latter option has a fairly high risk of thromboembolic complications, especially if the lead remains in place for a long time. In our case, we successfully explanted the lead percutaneously after a short period of anticoagulation and after verifying the absence of thrombus on transthoracic echocardiography.

\section{Conclusion}

The misplacement of pacemaker leads into the left heart chambers is an uncommon but easily diagnosed complication. To make the diagnosis, emphasis should 
be placed on a rigorous analysis of the post-implantation electrocardiogram and chest radiograph, which is cheap and widely available. This complication is easily confirmed by two-dimensional echocardiography, which also allows a search for an associated cardiac anomaly. In the absence of clear consensus, management is based on long-term oral anticoagulation or by surgical removal, or rarely by percutaneous reinsertion.

\section{Disclosure}

The authors report no conflicts of interest in this work.

\section{References}

1. Vanhercke D, Heytens W, Verloove H. Eight years of left ventricle pacing due to inadvertent malposition of a transvenous pacemaker lead in the left ventricle. Eur J Echocardiogr. 2008;9:825-827.

2. Tobin AM, Grodman RS, Fisherkeller M, Nicolosi R. Two-dimensional echocardiographic localization of a malpositioned pacing catheter. Pacing Clin Electrophysiol. 1983;6:291-299.

3. Gondi B, Nanda NC. Real-time two-dimensional echocardiography features of pacemaker perforation. Circulation. 1981;64:97-106.

4. Winner SJ, Boon NA. Transvenous pacemaker electrodes placed unintentionally in the left ventricle: three cases. Postgrad Med J. 1989;65: 98-102.

5. Mazzetti H, Dussaut A, Tentori C, Dussaut E, Lazzari JO. Transarterial permanent pacing of the left ventricle. Pacing Clin Electrophysiol. 1990;13:588-592.

6. Van Erckelens F, Sigmund M, Lambertz H, Kreis A, Reupcke C, Hanrath P. Asymptomatic left ventricular malposition of a transvenous pacemaker lead through a sinus venosus defect: follow-up over 17 years. Pacing Clin Electrophysiol. 1991;14:989-993.
7. Ross WB, Mohiuddin SM, Pagano T, Hughes D. Malposition of a transvenous cardiac electrode associated with amaurosis fugax. Pacing Clin Electrophysiol. 1983;6:119-124.

8. Van Gelder BM, Bracke FA, Oto A, et al. Diagnosis and management of inadvertently placed pacing and ICD leads in the left ventricle: a multicenter experience and review of the literature. Pacing Clin Electrophysiol. 2000;23:877-883.

9. Zaher MF, Azab BN, Bogin MB, Bekheit SG. Inadvertent malposition of a permanent pacemaker ventricular lead into the left ventricle which was initially missed and diagnosed two years later: a case report. JMed Case Rep. 2011;5:54.

10. Barold SS, Narula OS, Javier RP, Linhart JW, Lister JW, Samet P. Significance of right bundle branch block patterns during pervenous ventricular pacing. Br Heart J. 1969;31:285-290.

11. Okmen E, Erdinler I, Oguz E, et al. An electrocardiographic algorithm for determining the location of pacemaker electrode in patients with right bundle branch block configuration during permanent ventricular pacing. Angiology. 2006;57:623-630.

12. Shettigar UR, Loungani RR, Smith CA. Inadvertent permanent ventricular pacing from the coronary vein: an electrocardiographic, roentgenographic, and echocardiographic assessment. Clin Cardiol. $1989 ; 12: 267-274$

13. Klein HO, Beker B, Sareli P, DiSegni E, Dean H, Kaplinsky E. Unusual QRS morphology associated with transvenous pacemakers: the pseudo RBBB pattern. Chest. 1985;87:517-521.

14. Sharifi M, Sorkin R, Sharifi V, Lakier JB. Inadvertent malposition of a transvenous inserted pacing lead in the left ventricular chamber. $\mathrm{Am}$ J Cardiol. 1995;76:92-95.

15. Reising S, Safford R, Castello R, Bosworth V, Freeman W, Kusumoto F. A stroke of bad luck: left ventricular pacemaker malposition. JAm Soc Echocardiogr. 2007;20:1316. e1-e3.

16. Trohman RG, Wilkoff BL, Byrne T, Cook S. Successful percutaneous extraction of a chronic left ventricular pacing lead. Pacing Clin Electrophysiol. 1991;4:1448-1451.
International Medical Case Reports Journal

\section{Publish your work in this journal}

The International Medical Case Reports Journal is an international, peer-reviewed open-access journal publishing original case reports from all medical specialties. Previously unpublished medical posters are also accepted relating to any area of clinical or preclinical science. Submissions should not normally exceed 2,000 words or

\section{Dovepress}

4 published pages including figures, diagrams and references. The manuscript management system is completely online and includes a very quick and fair peer-review system, which is all easy to use. Visit $\mathrm{http}: / /$ www.dovepress.com/testimonials.php to read real quotes from published authors. 